\title{
Functional renal failure (FRF) in cirrhosis of the liver and liver carcinoma
}

\author{
P. VESIN \\ M.D.
}

\author{
H. TRAVERSO \\ M.D.
}

Villeneuve-St-Georges Hospital and Buenos Aires

\begin{abstract}
Summary
The term 'functional renal failure' has been used to describe the renal failure developing in advanced cirrhosis in which tubular function and structure remain intact. It may develop spontaneously, in which case prognosis is poor, but may be secondary to gastro-intestinal haemorrhage or excessive use of diuretics, in which case correction of the precipitating factor leads to improvement in renal function. It is suggested that the renal failure is due to a reduction in effective circulating plasma volume.
\end{abstract}

SINCE the initial paper by Hecker and Sherlock (1956), who reported the occurrence in patients with severe advanced liver cirrhosis of water and electrolyte disorders-azotaemia, hyponatraemia, oliguria - many studies have allowed for a better understanding of this picture, although its mechanisms remain poorly understood. In 1962, on the basis of careful pathological investigations in a large group of patients, we established that the picture of severe renal failure at the end-stage of liver cirrhosis could not be explained by the presence of anatomical renal lesions (Vesin, 1962). Therefore we coined the word 'functional'. This concept of functional renal failure (FRF) in the cirrhotic was later accepted by many authors, especially Lieberman (1970), Rodés et al. (1970) and Kew (1972). A striking confirmation of the anatomical integrity of the kidney in the cirrhotic with FRF was shown in the report by Koppel et al. (1969) that the transplantation of such kidneys could be successfully achieved with the recovery of function in the transplanted patient. Recently, Epstein et al. (1970) showed the post-mortem integrity of the renal vascular tree in these patients. All pertinent data will be found in the reviews by Vesin (1972b) and Kew (1972). In the course of these studies, it also appeared that there were less severe forms of FRF developing in the course of liver cirrhosis, namely bleedinginduced FRF and diuretic-induced FRF. These forms will also be dealt with in this paper, along with other aspects of special interest.

Reprint requests to: Dr P. Vesin, 31 rue de Moscou, 75008 Paris, France.

\section{Aetiological forms of FRF}

Bleeding-induced FRF

FRF is quite common, following gastro-intestinal (G-I) tract bleeding. Hyponatraemia and hyperkalaemia are moderate or absent and azotaemia and oliguria are the main findings noted. Refilling the vascular space rapidly leads to regression of azotaemia. A significant urine output is evidence of arrest of bleeding and recovery of renal irrigation.

\section{Diuretic-induced FRF}

Since the first paper of Vesin et al. (1962a), several studies have been devoted to this problem (Bosch et al., 1973; Reynolds, Lieberman and Redeker, 1967). To-day, it is quite easy in most cases to differentiate 'diuretic-induced FRF' from terminal FRF. The? clinical and biological findings are closely similar; however, the course is different. Diuretic-induced FRF is due to a significant fall in plasma volume and following the administration of plasma expanders, such as human serum albumin, functional recovery with increase in plasma volume and GFR and fall of azotaemia is achieved although, sometimes, it may require several weeks. However, the development of overt FRF in a cirrhotic patient following diuretic administration has a bad prognosis, and repeated bouts of FRF may accompany subsequent diuretic courses. It is uncommon to see the full picture of terminal FRF develop following diuretic administration; if so, it is probable that diuretics had been given at the onset of terminal FRF, playing a releasing or an accelerating role.

\section{Terminal FRF}

It is quite common in patients with advanced hepatic failure, and correlates well with the biological disorders which are evidence of the severity of the liver impairment (Arieff and Chidsey, 1974). It may develop spontaneously in patients never given diuretics (a rare occurrence nowadays) and who did not present with G-I tract bleeding. It is similar in many respects to diuretic-induced FRF-moderately increased azotaemia and creatininaemia, moderate 
hyperkalaemia-but oliguria, hyponatraemia, relative 'hypovolaemia', impaired RPF and GFR are definitely more conspicuous. The clinical course, except in a few cases, is usually fatal within weeks or may be more protracted, lasting 1 or 2 months. Death can be the result of cardio-vascular collapse or of hyperkalaemia-induced cardiac arrest (Acero $e t$ al., 1974). In most cases, renal failure per se is not responsible for death, but only accompanies portacaval encephalopathy or G-I tract bleeding. While the restoration of the blood and/or plasma volume usually results in the regression of diuretic-induced FRF, it is not so in terminal FRF. Restoration of the plasma volume is difficult to achieve and even more to maintain (Traverso et al., 1966); furthermore it is not accompanied by a regression of FRF (Traverso et. al., 1966; Tristani and Cohn, 1967; Vesin, 1962). To account for the mechanism of terminal FRF, we propose the following hypothesis. In the cirrhotic patient, there is an underlying distortion of systemic arterial circulation. The cardiac output is normal or even increased in most cases (Lancestremere et al., 1962; Tristani and Cohn, 1967), but blood supply is not regularly distributed. Skin and muscle irrigation is increased, cerebral and coronary circulation maintained, renal irrigation is reduced with decrease in the renal fraction of the cardiac output, resulting in renal hypoperfusion. At a critical stage of the disease, any further decrease in renal irrigation, for instance following a decrease in plasma volume, will lead to the development of terminal FRF. As total plasma volume is usually not much decreased, a concept of reduced 'effective' plasma volume has been proposed. Although not yet demonstrated, it fits well to the observed data. The relative maintenance of the total plasma volume is explained by the existence in the cirrhotic patient at earlier stages of the disease of a markedly increased plasma volume.

Many data point to a major, if not unique, role of effective plasma volume decrease in the development of terminal FRF.

(1) Péquignot et al. (1962) compared two groups of patients, one azotaemic, the other not. The mean plasma volume was smaller in the former group than in the latter one. We made similar observations. Of fifteen patients with favourable course, the plasma volume was 'normal' in three or increased in twelve; of sixteen patients with terminal FRF, it was 'normal' in eight or decreased in eight-never increased.

(2) Longitudinal studies of selected cases over several years showed that a fatal course was accompanied by a progressive reduction in plasma volume, not noted in patients who did not develop terminal FRF.

(3) The investigation of patients with severe FRF, first at the early stage of azotaemia and then before death, revealed a progressive and spontaneous in- crease in azotaemia and a significant fall in plasma volume values (Vesin et al., 1962b).

In our opinion, the intrarenal circulation anomalies (hypoperfusion of the outer renal cortex) reported by Kew et al. (1972) and by Epstein et al. (1970) are only the result of the global hypoperfusion of the kidney. A similar explanation might account for the high increase in plasma renin activity reported by Schroeder et al. (1970).

The strikingly reduced renal blood flow may also be the cause of severe renal vaso-constriction; it should be noted that the recent studies of Arieff and Chidsey (1974) showed that in terminal FRF, PG-A a powerful vasodilator, could not improve renal plasma flow and GFR. The severe hypoperfusion syndrome is precipitated by a decrease in total plasma volume, resulting in a reduced 'effective' plasma volume. This 'effective' plasma volume decrease is responsible for the great increase in proximal tubular resorption of fluid and electrolytes, with loss of efficiency of distal diuretics (Vesin, 1962), and shown by the experimental studies of Weiner et al. (1971).

Terminal FRF in patients with primary or metastatic carcinoma of the liver

We have described this picture in two patients with liver cirrhosis and hepatoma and in three patients with liver metastases without cirrhotic lesions (Vesin, Roberti and Viguié, 1965). Kew et al. (1972) extended our findings with the study of a further fourteen patients; they showed that the haemodynamic changes were similar to those seen in cirrhotic patients with terminal FRF.

\section{Differential diagnosis of FRF from chronic nephritis in patients with liver cirrhosis}

This is usually easy. If testing for the presence in the urine of red cells, casts or proteinuria is of no avail, the following observations are of great help to the diagnosis of FRF : terminal FRF develops a long time after the initial diagnosis of cirrhosis, oliguria sets in earlier, azotaemia is less marked, as well as creatininaemia and hyperkalaemia, the concentration of urea in the urine is higher in FRF than in chronic nephritis.

\section{Treatment}

Volume restoration is usually effective in haemorrhage-induced and diuretic-induced FRF. It is ineffective in most cases of terminal FRF in liver cirrhosis and liver carcinoma, although some unexpected good results 'make a serious therapeutic trial mandatory. The main guidelines are the following.

(1) Cessation of diuretic administration, although 
in a few cases the association of large doses of furosemide and blood volume expanders may be transiently effective. Ascites should not be tapped.

(2) Blood volume expansion by means of blood, plasma, plasma expanders, especially human serum albumin deficient in salt, and ascites infusion.

(3) Water intake restriction may help to reduce hyponatraemia. Mannitol infusions are usually ineffective. Sodium chloride administration should be avoided. Dialysis may control hyponatraemia, but does not improve renal function.

(4) Potassium chloride or potassium-rich food must be withheld to limit hyperkalaemia. Potassiumbinding resins may be useful.

(5) Vasodilators (acetylcholine, PG- $A_{1}$ ) or sympathomimetic amines (metaraminol, etc.) are useless.

\section{References}

Acero, D., Rodés, J., Arroyo, V. \& Bosch, J. (1974) La hiperpotasemia como causa de muerte en la cirrosis hepática. Revista clínica española, 132, 423.

ARIEFF, A.I. \& CHIDSEY, C.A. (1974) Renal function in cirrhosis and the effects of prostaglandin $\mathrm{A}_{1}$. American Journal of Medicine, 56, 625.

Bosch, J., Arroyo, V., Rodes, J., Teres, J., Bordas, J.M. \& Bruguera, M. (1973) Insuficiencia renal inducida por diuréticos en la cirrosis hepática con ascitis. Revista clínica española, 131.

Epstein, M., Berk, D.P., Hollenberg, N.K., Adams, D.F., Chalmers, T.C., Abrams, H.L. \& Merril, J.P. (1970) Renal failure in the patient with cirrhosis. American Journal of Medicine, 49, 175.

HeCker, R. \& Sherlock, S. (1956) Electrolyte and circulatory changes in terminal liver failure. Lancet, ii, 1121.

Kew, M. (1972) Progress report. Renal changes in cirrhosis. Gut, 13, 748.

Kew, M.C., Limbrick, C.A., Varma, R.R. \& Sherlock, S. (1972) Renal blood flow in malignant disease of the liver. Gut, 13, 421.

KeW, M.C., Varma, R.R., Williams, H.S., BrUnt, P.W., Hourigan, K.J. \& Sherlock, S. (1971) Renal and intrarenal blood flow in cirrhosis of the liver. Lancet, i, 504.

Koppel, M.H., Coburn, J.W., Mims, M.M., Goldstein, H., Boyle, J.D. \& RubINI, M.E. (1969) Transplantation of cadaveric kidneys from patients with hepato-renal syndrome. Evidence for the functional nature of renal failure in advanced liver disease. New England Journal of Medicine, 280, 1367.

Lancestremere, R.G., Davidson, P.L., EARley, L.E., O'Brien, F.J. \& PAPPER, S. (1962) Renal failure in Laen- nec's cirrhosis. II. Simultaneous determination of cardiac output and renal hemodynamics. Journal of Clinical Investigation, 41, 1922.

LIEBERMAN, F.L. (1970) Functional renal failure in cirrhosis. Gastroenterology, 58, 108.

Péquignot, G.E., Viallet, A., Combrisson, A. \& Caroli, J. (1962) L'hypovolémie relative des cirrhotiques hyperazotémiques. Circonstances d'apparition. In: Aktuelle Probleme der Hepatologie (Ed. by G. A. Martini), p. 110. Georg Thieme Verlag, Stuttgart.

Reynolds, T.B., Lieberman, F.L. \& Redeker, A.G. (1967) Functional renal failure with cirrhosis. The effect of plasma expansion therapy. Medicine, 46, 191.

Rodés, J., Bruguera, M., Teres, J. \& Bordas, J.M. (1970) $\mathrm{La}$ insuficiencia renal funcional terminal (IRFT) de la cirrosis hepática con ascitis. Revista clínica española, 31, 475.

Schroeder, E.T., Eich, R.H., Smulyan, H., Gould, A.B. \& GABUzDA, G.J. (1970) Plasma renin level in hepatic cirrhosis. Relation to functional renal failure. American Journal of Medicine, 49, 186.

Traverso, H., Vesin, P., Combrisson, A., Besson, P. \& Catran, R. (1966) Charge intraveineuse d'albumine dans les cirrhoses ascitiques. Etude biologique. Semaine des hôpitaux de Paris, 40, 17.

TRISTANI, F.E. \& CoHN, J.N. (1967) Systemic and renal hemodynamics in oliguric hepatic failure: effect of volume expansion. Journal of Clinical Investigation, 46, 1894.

VESIN, P. (1962) Late functional renal failure in cirrhosis with ascites: pathophysiology, diagnosis and treatment. In: Aktuelle Probleme der Hepatologie (Ed. by G. A. Martini), p. 98. Georg Thieme Verlag, Stuttgart.

VESIN, P. (1972a) Water, electrolyte, and acid-base disorder in liver disease. In: Clinical Disorders of Fluid and Electrolyte Metabolism. (Ed. by M. H. Maxwell and C. R. Kleeman), p. 873. McGraw Hill Inc., New York.

VESIN, P. (1972b) L'insuffisance rénale fonctionnelle du cirrhotique. Evolution, mécanisme, traitement. Archives françaises des Maladies de l'Appareil Digestif, 61, 775.

Vesin, P., Roberti, A. \& Viguie, R. (1965) Défaillance rénale fonctionnelle terminale chez des malades atteints de cancer du foie primitif ou secondaire. Semaine des hopitaux de Paris, 41, 1216.

Vesin, P., Rueff, B., Traverso, H., Hirsch-Marie, H. \& CatTan, R. (1962a) L'insuffisance rénale fonctionnelle du cirrhotique ascitique. Etude critique du rôle des diurétiques. Bulletin et mémoires de la Société Médicale des hôpitaux de Paris, 113, 787.

Vesin, P., Traverso, H., Hirsch-Marie, H. \& Cattan, R. (1962b) L'insuffisance rénale circulatoire spontanée du cirrhotique. Son évolution. Semaine des hôpitaux de Paris, 386, 3598.

Weiner, M.W., Weinman, E.J., Kashgarian, M. \& HaysLETT, J.P. (1971) Accelerated reabsorption in the proximal tubule produced by volume depletion. Journal of Clinical Investigation, 50, 1379. 